$$
\text { CONF-960706.-23 }
$$

\title{
HIGH FLUX ISOTOPE REACTOR \\ REDESIGNED BERYLLIUM REFLECTOR \\ THERMAL STRESS CALCULATIONS
}

\author{
S. J. Chang \\ Research Reactors Division \\ Oak Ridge National Laboratory \\ Oak Ridge, Tennessee
}

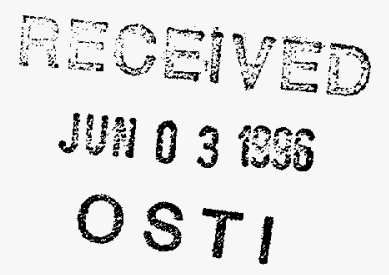

Presented at

American Society for Mechanical Engineers (ASME)

Pressure Vessels, Piping, and ICPVT-8 Conference

Montreal, Canada

July 22-26, 1996

\begin{abstract}
"The submitted manuscript has been authored by a contractor of the U.S. Government under contract No. DEAC05-96OR22464. Accordingly, the

U.S. Government retains a nonexclusive, royalty-free license to publish or reproduce the published form of this contribution, or allow others to do so, for U.S. Government purposes."
\end{abstract}

Prepared by the Research Reactors Division

OAK RIDGE NATIONAL LABORATORY

Oak Ridge, Tennessee 37831 managed by

LOCKHEED MARTIN ENERGY RESEARCH CORP.

for the

U.S. DEPARTMENT OF ENERGY under contract DE-AC05-96OR22464 


\section{DISCLAIMER}

Portions of this document may be illegible in electronic image products. Images are produced from the best available original document. 


\title{
HIGH FLUX ISOTOPE REACTOR REDESIGNED BERYLLIUM REFLECTOR THERMAL STRESS CALCULATIONS
}

\author{
S. J. Chang \\ Research Reactors Division \\ Oak Ridge National Laboratory \\ Oak Ridge, Tennessee 37831
}

\begin{abstract}
The Beryllium reflector of the High Flux Isotope Reactor is currently redesigned for upgrading the capability of the reactor. The original design criteria are adopted in the redesign analysis. Both nuclear heating and thermal stress calculations are revised. The results show that more margin of safety have been achieved and the updated design assures more precise design estimates for the reflector thermal stress conditions.
\end{abstract}

\subsection{INTRODUCTION}

The beryllium permanent reflector of the High Flux Isotope Reactor (HFIR) is heated by nuclear reaction of the reactor core fission products and by the targets that contain radioactive materials undergone nuclear reaction. The reactor core area is surrounded by the reflector for moderating the neutrons and the target rods are located within the reflector for the needed nuclear reactions. The reflector is cooled by water flowing through the densely distributed cooling holes of 1/8 inches in diameter along the longitudinal direction of the reflector. Both heating rates have been calculated by J. C. Gehin of the Engineering Physics Division through the Monte Carlo code MCNP. The present calculation is to estimate the temperature and the thermal stress distributions of the reflector by applying the finite element code ABAQUS, as a part of the reflector redesign task.

Design criteria adopted in this reflector redesign analysis include the following considerations. Radiation damage resulting from the intense high energy $(E>1.0 \mathrm{Mev}$ ) neutron flux up to $2 x$ $10^{22}$ nvt is considered acceptable, based on MTR experience. Allowable thermal stress based on tests for unirradiated beryllium showed a minimum thermal stress at failure of $28,200 \mathrm{psi}$. The design value of $12,000 \mathrm{psi}$ at $125 \mathrm{MW}$ is chosen. The sources of heat generation considered in the redesign

'Based on work performed at Oak Ridge National Laboratory, managed by Lockheed Martin Energy Research Corporation., for the U.S. Department of Energy under contract DE-AC05-960R22464. Accordingly, the U.S. government retains a nonexclusive, royal-free license to publish or reproduce the published form of this contribution, or allow others to do so, for U.S. government purposes. calculations are due to nuclear fission from various sources and will be described later. The water fraction affects thermal flux and reactivity. A fraction of $0.6 \%$ change in reactivity is equivalent to about one day of core lifetime, the reflector water content should be kept as low as possible. A design criterion is the requirement for the minimum reflector water content.

A three-dimensional finite element model of 6423 elements is used to represent the reflector. Several assumptions are made. The model does consider the geometry of the target holes, but not the beam tube holes nor the cooling holes. All finite element calculations are based on the 3-D heat source distribution obtained by J. C. Gehin as a result of his Monte Carlo code MCNP calculation. Heat removal from cooling holes in the three dimensional calculations is approximately represented by a distribution of heat sinks.

To study the effect of the cooling holes, the refined twodimensional finite element mesh across the midplane of the reflector is also constructed. The midplane heating rate is assumed in the calculation. The heating rate was also based on the Monte Carlo result of J. C. Gehin. This heating rate produces steeper temperature gradient and, therefore, gives conservative thermal stress distributions. The heating rate of the $\mathrm{Np}$ target fission at the reflector is also obtained from the Monte Carlo results. All free surfaces of the permanent reflector are assumed to be insulated in the temperature calculation.

\subsection{CALCULATION INPUTS \\ 1 Reflector Geometry}

The shape of the permanent beryllium reflector is a hollow cylinder. It encloses the adjacent removable reflector, the control plates, and the fuel elements. The reflector has inner radius of 25 inches, outer radius 43 inches and height of 24 inches. Longitudinal coolant holes of $1 / 8$ inch in diameter are distributed across the horizontal sections of the reflector. Heat is removed by the cooling water passing through these holes. The cooling holes are located along seven concentric circles with ninety 
holes per each circle. The seven radii are $13.00,13.83,14.83$, $15.96,17.22,18.68$ and 20.38 inches, respectively. The average heat transfer coefficient on the hole surface is estimated to be $5000 \mathrm{Btu} / \mathrm{hr}-\mathrm{ft}^{2}-^{\circ} \mathrm{F}$.

\section{Beryllium Material Properties}

\begin{tabular}{|c|c|}
\hline Density & $\begin{array}{l}y=1.84 \mathrm{gm} / \mathrm{cc}=1.722 \times 10^{-4} \mathrm{lb} \\
\mathrm{s}^{2} / \mathrm{in} .{ }^{4}\end{array}$ \\
\hline Thermal conductivity & $\begin{array}{l}\mathrm{K}=5.83 \mathrm{Btu} / \mathrm{hr} \text { in }{ }^{\circ} \mathrm{F}= \\
1.7083 \text { watts/in }{ }^{\circ} \mathrm{F}\end{array}$ \\
\hline $\begin{array}{l}\text { Heat capacity } \\
\text { Coef thermal expansion } \\
\text { Modulus of elasticity }\end{array}$ & $\begin{array}{l}C_{p}=1.2793 \text { watts sec/gm }{ }^{\circ} \mathrm{F} \\
\alpha=9 \times 10^{-6} 1 /{ }^{\circ} \mathrm{F} \\
E=40 \times 10^{6} \mathrm{psi}\end{array}$ \\
\hline Poisson's ratio & $v=0.024$ \\
\hline
\end{tabular}

The reflector heating calculations obtained by Gehin include the following nuclear reactions from the reactor core. Two types of calculations are made to estimate the total heat load. The first type of calculation is a coupled neutron-photon problem that gives the neutron heating and the prompt photon heating. The prompt photon heating consists of prompt fission photons, capture photons, and inelastic scatter photons. A subsequent photon-only calculation is performed to compute the heating due to fission product decay.

The distribution of the heat load throughout the reflector has been tabulated. The caiculations involve both the reflector and the water heat loads for 22 and 27 inches control rod positions. The results of Gehin have been compared by him to those performed by $D$. R. Vondy in the early 1960's for the original design of HFIR. The results of Vondy in his 1963 calculation and that of Gehin show good agreement.

The tabulated values of Gehin were analytically interpolated by exponential representation of the following form:

$$
y=A \cdot B^{x}
$$

Where $\boldsymbol{A}$ and $\boldsymbol{B}$ are constants that depend on the zone regions along the axial direction of the reflector. The unit for $y$ is watts/gm per $1 \mathrm{MW}$ of reactor power. The variable $\boldsymbol{x}$ is the radial distance in centimeter from the axis of the reflector.

\begin{tabular}{|c|c|c|}
\hline Zone & $\boldsymbol{A}$ & $\boldsymbol{B}$ \\
\hline 1 & 0.258736 & 0.926595 \\
\hline 2 & 0.470268 & 0.920382 \\
\hline 3 & 0.650347 & 0.916763 \\
\hline 4 & 0.707529 & 0.915892 \\
\hline
\end{tabular}

The zoning of the reflector along its axial direction is made by Gehin to seven blocks. The heat load is symmetrically distributed across the midplane by the reflector. The above tabulated values of $\boldsymbol{A}$ and $\boldsymbol{B}$, therefore, only need four zone values, in which zone four corresponds to values at the midplane of the reflector.

Nuclear heating of last section is removed through cooling holes of $1 / 8$ inch in diameter distributed along seven concentric circles from the axis of the reflector. As described earlier, ninety holes are located evenly along each circle.

For the three-dimensional application of ABAQUS to calculate the temperature distribution, the $7 \times 90$ small heat removal holes are idealized and equivalently represented by a distribution of heat sinks. This idealization is needed because modeling by finite element method, including the coolant holes, requires a great number of elements that are beyond the capability of the machine memory. The effects of small cooling hole are later studied by using the ABAQUS two-dimensional calculation.

For the three-dimensional calculation, an equivalent heat sink distribution is obtained by the following expression:

$$
y=0.019067 x^{2}-0.750888 x+7.82494
$$

The unit of $y$ in the above equation is holes $/ \mathrm{in}^{2}$.

The above equation is obtained by dividing the two-dimensional horizontal section of the cylinder to a distribution of areas. Each area contains only one cooling hole. The inverse of that area is represented by the above equation. The quantity $y$ that is multiplied by the rate of heat removal from one cooling hole is the rate of heat removal per unit area of the horizontal cross section of the beryllium cylinder.

The heat transfer coefficient is estimated as

$$
h=5000 \frac{\mathrm{Btu}}{{\mathrm{hr} \cdot \mathrm{ft}^{2} \cdot{ }^{\circ} \mathrm{F}}}
$$

The cooling hole is $1 / 8$-inch in diameter and the beryllium cylinder is 24 inches long. Therefore, the rate of heat removal (Btu/hr) per unit volume $\left(\mathrm{in}^{3}\right)$ is

$$
y \times h \times \frac{\pi}{8} \times \frac{T-T w}{24} \times \frac{1}{12^{2}}
$$

Where $T-T w$ is the temperature rise from water temperature $T w$.

\section{Target Heating Calculation}

Np fission is used as the feed material to also generate heat in the reflector. The tabulated heating rate obtained by Gehin is 
interpolated analytically. The expression is used in the temperature and stress calculations.

Results obtained by Gehin show that the heating is axisymmetric and the rate varies along the axial direction of the target hole. Also, the heating rate is symmetrical across the midplane of the reflector perpendicular to the axis of the target. The calculation was made by dividing the axial direction of the target to a total of seven regions. Because of symmetry, there are only four distinct heating distribution regions.

The four heating rates are represented by

$$
y=A \cdot x^{3}+B \cdot x^{2}+C \cdot x+D
$$

\begin{tabular}{c|c|c|c|c}
\hline Region & $\mathrm{A}$ & $\mathrm{B}$ & $\mathrm{C}$ & $\mathrm{D}$ \\
\hline 1 & -0.00281518 & 0.071928 & -0.643756 & 2.27456 \\
\hline 2 & -0.00455474 & 0.117370 & -1.06117 & 3.81361 \\
\hline 3 & -0.00533142 & 0.138374 & -1.26517 & 4.61295 \\
\hline 4 & -0.00559865 & 0.145272 & -1.33003 & 4.86546 \\
\hline
\end{tabular}

The unit of $y$ is watts per gram of beryllium and per $1 \mathrm{MW}$ power of the power generated by one target. The unit of the radial distance $\boldsymbol{x}$ from the target axis is expressed in centimeter. The target power is estimated by him as $0.08 \mathrm{MW}$.

\section{CALCULATION AND ANALYSIS}

In the three-dimensional finite element model, the target holes have been modeled, but both the small cooling holes and the beam tube hole are not included in the model. An additional twodimensional finite element analysis is made in which the cooling holes are modeled and more refined temperature distribution is obtained.

\section{Three-Dimensional Finite Element Calculation}

Three-dimensional heat conduction equation is used to calculate the transient temperature distribution,

$$
K\left(\frac{\partial^{2}}{\partial x^{2}}+\frac{\partial^{2}}{\partial y^{2}}+\frac{\partial^{2}}{\partial z^{2}}\right) T=\gamma C_{p} \frac{\partial T}{\partial t}-Q
$$

Where $Q$ is the sum of the radiation heating sources and the heat removal source, $K$ is the heat conduction coefficient, and $r_{p}$ is the heat capacity per unit volume.

In the finite element calculation, the heat source is applied instantly and the equilibrium maximum temperature generated is approximately $22^{\circ} \mathrm{F}$ that appears along the midplane at the inner surface of the permanent reflector. At the outer surface, the equilibrium temperature is $10^{\circ} \mathrm{F}$.
The corresponding thermal stress at the equilibrium temperature is shown in Fig. 1. The maximum von Mises stress is $6.0 \mathrm{ksi}$ shown in Fig. 2. It appears also along the midplane at the inner surface of the permanent reflector. The tensile stress of approximately $2.5 \mathrm{ksi}$ appears along the midplane at the outer surface of the reflector. Tensile stress will promote cracking. This will have a pronounced effect when the beryllium is embrittled after years of radiation and helium gas attack.

\section{Two-Dimensional Analysis for Effect of Cooling Holes and the Target Heating}

For a refined study on the stress distribution along the cooling holes, two-dimensional finite element model is constructed. The results show that the maximum equilibrium temperature is approximately $40^{\circ} \mathrm{F}$ and the maximum compressive stress is approximately $2.5 \mathrm{ksi}$ at the inner surface of the reflector. The tensile stress of $2.0 \mathrm{ksi}$ at the surfaces of the cooling holes. The ring structure of the hollow cylinder will produce approximately $5 \mathrm{ksi}$ tensile stress at the outer edge of the reflector. These stresses will be added up to $7 \mathrm{ksi}$ tensile stress at the inner surfaces of the cooling holes. For a multiplication factor of 1.25 due to the design power of $125 \mathrm{MW}$, the maximum tensile stress is $8.75 \mathrm{ksi}$ that is much less than the design allowable of $12 \mathrm{ksi}$.

The effect of target heating is relatively small. Each target produces approximately $1^{\circ} \mathrm{F}$ temperature rise. A cluster of four targets produces temperature rise of $5^{\circ} \mathrm{F}$ that is the result of the accumulated heat trapped in the central region surrounded by the cluster of four targets. Cluster of more than four does not produce additional temperature increase than that by four. The target heating, therefore, is insignificant.

\section{CONCLUSIONS}

Temperature and thermal stress distributions in the present reflector design calculation need to be raised by a factor of 1.25 if a $125 \mathrm{MW}$ power is considered as the design load. As shown in the last section, the maximum tensile stress at the inner surface of the cooling hole is $8.75 \mathrm{ksi}$. The temperature and thermal stress are in general smaller then those shown in HFIR original design calculations. Apparently, it is due to the progress of computation and modeling method. The original design stress is approximately equal to $12 \mathrm{ksi}$.

\section{REFERENCE}

Chang, S. J., Gehin, J. C., Hambaugh, P. C., Rothrock, R. B., and Smith, L. A., High Flux Isotope Reactor (HFIR) Permanent Reflector Redesign Study, ORNL/RRD/INT-107, September 1995 


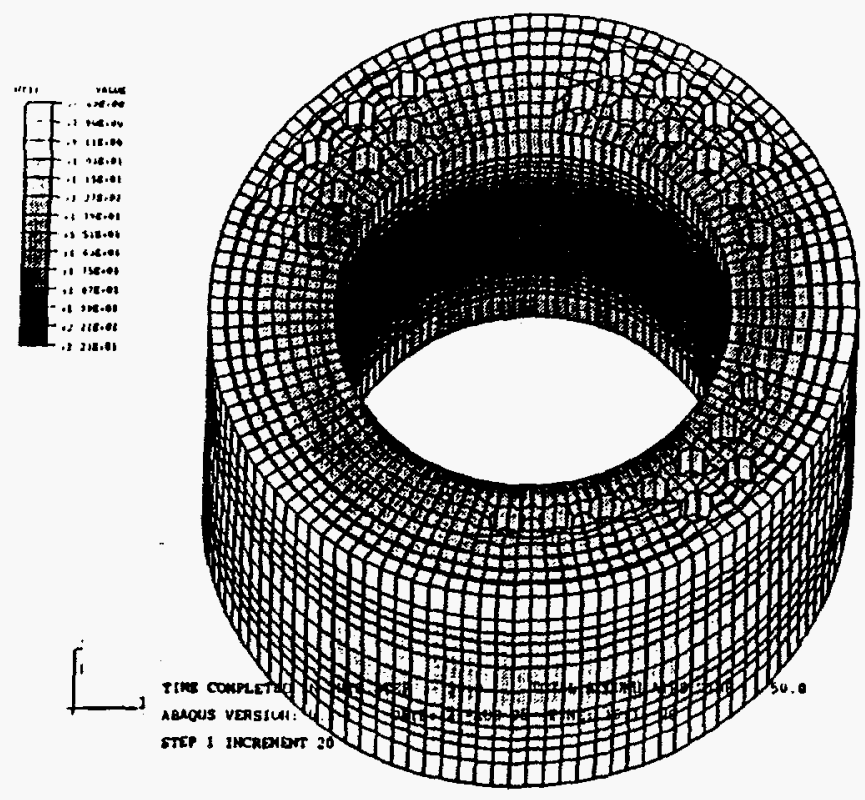

Figure 1. Equilibrium temperature distribution for the redesigned HFIR permanent reflector at $100 \mathrm{MW}$ reactor power. Nuclear heating is based on the Monte Carlo code MCNP results. No target heating is considered in this temperature distribution.

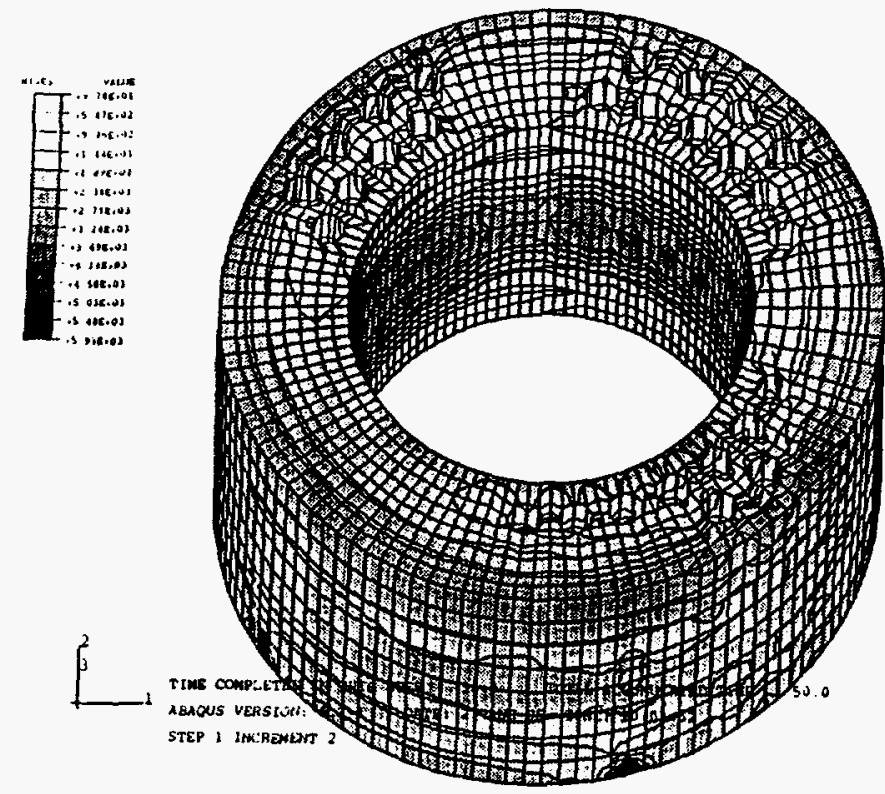

Figure 2. Equilibrium thermal stress ( von Mises stress) distribution for the redesigned HFIR permanent reflector at 100 MW reactor power. Nuclear heating is based on the Monte Carlo code MCNP results. No target heating is considered in this thermal stress distribution.

\section{DISCLAIMER}

This report was prepared as an account of work sponsored by an agency of the United States Government. Neither the United States Government nor any agency thereof, nor any of their employees, makes any warranty, express or implied, or assumes any legal liability or responsibility for the accuracy, completeness, or usefulness of any information, apparatus, product, or process disclosed, or represents that its use would not infringe privately owned rights. Reference herein to any specific commercial product, process, or service by trade name, trademark, manufacturer, or otherwise does not necessarily constitute or imply its endorsement, recommendation, or favoring by the United States Government or any agency thereof. The views and opinions of authors expressed herein do not necessarily state or reflect those of the United States Government or any agency thereof. 